\title{
Towards the Physical Map of the Trypanosoma cruzi Nuclear Genome: Construction of YAC and BAC Libraries of the Reference Clone T. cruzi CL-Brener
}

\author{
I Ferrari, H Lorenzi, MR Santos*, S Brandariz, JM Requena**, A Schijman, \\ M Vázquez, JF da Silveira*, C Ben-Dov, C Medrano, S Ghío, P López Bergami, \\ I Cano*, B Zingales***, TP Urmenyi ${ }^{* * *}$, E Rondinelli****, \\ A González ${ }^{* * * *}$, A Cortes*****, MC Lopez $* * * * *$, MC Thomas*****, \\ C Alonso**, JL Ramírez $* * * * *$, MA Chiurrillo $* * * * *$, R Rangel Aldao*******, \\ A Brandão $0^{* * * * * * *}$, W Degrave $* * * * * * * *$, V Perrot, $* * * * * * * * *$, \\ M Saumier*********, A Billaut*********, D Cohen*********, \\ D Le Paslier $* * * * * * * * *$, MJ Levin/ ${ }^{+}$
}

Instituto de Investigaciones en Ingeniería Genética y Biología Molecular (INGEBI, CONICET, FCYEN-UBA), Obligado 2490, 1428 Buenos Aires, Argentina *Escola Paulista de Medicina, Rua Botucatu 862, São Paulo, SP, Brasil ** CBM, Madrid, España ***Universidade de São Paulo, São Paulo, SP, Brasil ****Universidade Federal do Rio de Janeiro, CCS, Ilha do Fundão, Rio de Janeiro, RJ, Brasil *****IPB, Granada, España $* * * * * *$ Universidad Central de Venezuela, Apdo 47525, Caracas, Venezuela *******USB, Sartenejas, Caracas, Venezuela $* * * * * * * *$ Instituto Oswaldo Cruz, Av. Brasil 4365, Rio de Janeiro, RJ, Brasil *********CEPH, 27

Rue Juliette Dodou, 75010 Paris, France

Strategies to construct the physical map of the Trypanosoma cruzi nuclear genome have to capitalize on three main advantages of the parasite genome, namely $(a)$ its small size, $(b)$ the fact that all chromosomes can be defined, and many of them can be isolated by pulse field gel electrophoresis, and (c) the fact that simple Southern blots of electrophoretic karyotypes can be used to map sequence tagged sites and expressed sequence tags to chromosomal bands. A major drawback to cope with is the complexity of T. cruzi genetics, that hinders the construction of a comprehensive genetic map. As a first step towards physical mapping, we report the construction and partial characterization of a T. cruzi $C L$ Brener genomic library in yeast artificial chromosomes (YACs) that consists of 2,770 individual YACs with a mean insert size of $365 \mathrm{~kb}$ encompassing around 10 genomic equivalents. Two libraries in bacterial artificial chromosomes (BACs) have been constructed, BACI and BACII. Both libraries represent about three genome equivalents. A third BAC library (BAC III) is being constructed. YACs and BACs are invaluable tools for physical mapping. More generally, they have to be considered as a common resource for research in Chagas disease.

Key words: Trypanosoma cruzi - genome project - physical map - YAC library - BAC library - sequence tagged sites (STS) - expressed sequence tags (EST)

This work was supported by: Project Genome Trypanosoma cruzi, INGEBI-CEPH, Ministere d'Affaires Etrangeres, France - Ambassade de France en Argentine; Trypanosoma cruzi Genome Project-Subprograma IIIBiotecnología - CYTED Programa Iberoamericano de Ciencia y Tecnología para el Desarrollo; the United Nations Development Program for Research and Training in Tropical Diseases (WHO/TDR); INSERM-CONICET cooperation program; Trypanosoma cruzi Genome Project associated to the Human Genome Project of the University of Buenos Aires (Ex203-Ex283SECyT-UBA); Fundación Antorchas, and European Commission Contract No. 936018 AR.; CNPq/PADCT, Brazil; FAPESP, Brazil.

${ }^{+}$Corresponding author. Fax: +54-1-7868578. E-mail: mlevin@proteus.dna.uba.ar

Received 20 August 1997

Accepted 10 September 1997
Since the characterization of the first cases of Chagas disease caused by the parasitic protozoan Trypanosoma cruzi (Chagas 1909, Rosenbaum 1964), researchers in Latin America have been attracted to it. During the past 10 years, more than 50 parasite genes have been cloned in our continent, and many immunological features of the disease have been established (HontebeyrieJoskowicz \& Minoprio 1991, Levin 1991, Andrews 1993, Aldao 1993, Mosca \& Briceño 1993, Gomes 1995, González \& Moro 1995, Pereira-Chioccola et al. 1995, Urbina 1995). With support from national health services and international agencies $T$. cruzi became a key model organism for laboratories in the region, and was adopted by laboratories 
in other countries of the continent, and overseas. Therefore, it was inevitable and logical to propose and launch the T. cruzi genome project, as a joint venture between laboratories from Central and South America and laboratories from developed countries.

The first step toward the characterization and sequencing of the T. cruzi genome is the construction of its physical map. Strategies to attain this objective have to capitalize on three main advantages of the parasite genome, namely (a) its small size, (b) the fact that all chromosomes can be defined, and many of them can be isolated by pulse field gel electrophoresis (PFGE), and (c) the fact that simple Southern blots of electrophoretic karyotypes can be used to map sequence tagged sites (STS) and expressed sequence tags (EST) to chromosomal bands. A major drawback to cope with is the complexity of $T$. cruzi genetics, that hinders the construction of a comprehensive genetic map: the parasite reproduces asexually by binary fission, has a clonal population structure, and due to poor chromatin condensation, chromosomes can not be visualized (Solari 1980, Tibayrenc \& Ayala 1988).

An initial experimental strategy for producing a high-resolution physical map of the T. cruzi 87 $\mathrm{Mb}$ genome should be based on large genomic fragments cloned in yeast artificial chromosomes (YACs) (Burke et al. 1987, Smith 1994) and bacterial artificial chromosomes (BACs) (Shizuya et al. 1992, Wang 1994), which can be assigned to genomic locations by hibridization with different markers and chromosome specific probes.

YACs were chosen because of the large DNA fragments that can be accomodated. The initial reliance on YAC clones was justified because previous works showed that YACs containing T. cruzi genomic fragments were stable and the cloned sequences were colinear with the genomic ones from which they derived (Ajioka \& Swindle 1993, Don 1995). Moreover, YACs have been successfully used to clone genomic fragments of another protozoan parasite, Plasmodium falciparum. They were employed to disclose the structure of $P$. falciparum chromosomes (Lanzer 1993, de Bruin 1994). In turn, the P. falciparum genome consortium constructed the YAC library of the project to serve as a common resource in whole genome mapping of this microorganism (The Wellcome Trust Malaria Genome Collaboration 1995).

More recently, a cloning system based on BACs has been developed, which appears to offer a reasonable compromise between the technical advantages of cosmids, which harbor insertions of no more than $35 \mathrm{~kb}$, and the larger DNA insert size of YACs. The BAC system is based on the single copy plasmid F factor of Escherichia coli (Shizuya
1992, Wang 1994), that is capable of maintaining foreign DNA fragments of more than $200 \mathrm{~kb}$, with a high degree of structural stability. In fact, the F factor not only codes for genes that are essential to regulate its own replication but also controls its copy number. The pBAC vector incorporates these essential genes as well as a chloramphenicol resistance marker and a multiple-cloning site (Shizuya 1992, Wang 1994). As discussed below, this system has been assigned a primary role in the $T$. cruzi project.

Herein we report the construction and partial characterization of large DNA insert libraries of the T. cruzi nuclear genome in YAC and BAC vectors, which will serve as backbones of the physical map of this complex genome.

\section{MATERIALS AND METHODS}

Trypanosoma cruzi CL-Brener, reference clone of the project - Genomic DNA used to construct the libraries was derived from the reference clone T. cruzi CL-Brener maintained and distributed by Dr B Zingales (USP, São Paulo, Brazil; see the corresponding article in this volume).

Preparation of T. cruzi CL-Brener genomic $D N A$ - Epimastigotes were grown at the Dept. of Immuno Parasitology of the Pasteur Institut, Paris, France, by Dr Paola Minoprio, and at the Escola Paulista de Medicina, São Paulo, Brazil, by Dr J Franco da Silveira. Parasites were harvested, counted and included in an agarose matrix, in order to protect genomic DNA from mechanical rupture (Dausset 1992). Briefly, freshly harvested parasite cells were loaded onto $1 \%$ low melting point agarose buffered in PBS $(136 \mathrm{mM} \mathrm{NaCl}, 2.7 \mathrm{mM}$ $\mathrm{KCl}, 10 \mathrm{mM} \mathrm{Na}_{2} \mathrm{HPO}_{4}, 1.75 \mathrm{mM} \mathrm{KH}_{2} \mathrm{PO}_{4}$ ) to prepare $100 \mu \mathrm{l}$ volume plugs containing approximately $20 \mu \mathrm{g}$ of DNA per plug. Agarose plugs were incubated overnight in NDS $(0.5 \mathrm{M}$ EDTA, $0.1 \mathrm{M} \mathrm{NaCl}$, $1 \%$ N-lauroyl- sarcosine $\mathrm{pH} 8.0$ ) with $1 \mathrm{mg} / \mathrm{ml}$ proteinase K (Boehringer Mannheim, Germany) at $50^{\circ} \mathrm{C}$ and washed several times in $50 \mathrm{ml}$ TE $(10$ $\mathrm{mM}$ Tris- $\mathrm{HCl} \mathrm{pH}$ 7.5, 1 mM EDTA).

Construction of YAC libraries

Partial digestion of DNA - T. cruzi embedded DNA was partially digested with EcoRI; plugs were preincubated in digestion buffer containing $10 \mathrm{mM}$ $\mathrm{MgCl}_{2}$ and EcoRI was added at a ratio of $5 \mathrm{U} / \mu \mathrm{g}$ of DNA and incubated at $37^{\circ} \mathrm{C}$ for $1 \mathrm{hr} 30 \mathrm{~min}$. The reaction was stopped by addition of EDTA to a final concentration of $20 \mathrm{mM}$. DNA size fractionation was followed by analytical PFGE.

Preparative PFGE of digested DNA - The partially digested DNA was size-fractionated using a contour clamped homogeneous electric field apparatus (CHEF II, BioRad, California, USA). The gel (0.5x TBE, $0.8 \%$ low melting point agarose) 
was electrophoresed at $140 \mathrm{~V}$, for $18 \mathrm{hr}$ at $12^{\circ} \mathrm{C}$, with a pulse time of $60 \mathrm{sec}$. In these conditions, fragments above $400 \mathrm{~kb}$ concentrated in the compression zone of the gel. A gel slice containing the compression zone was removed and equilibrated with ligation buffer (see below).

Preparation of vector - The vector pYAC4 was linearized by BamHI digestion, and the ends dephosphorylated. After phenol extraction and ethanol precipitation, the pYAC4 cloning site was cleaved with Eco RI.

DNA ligations - The agarose slice containing size-selected digested DNA was washed twice in ligation buffer $(66 \mathrm{mM}$ Tris- $\mathrm{HCl}, \mathrm{pH} 7.5 ; 10 \mathrm{mM}$ $\mathrm{MgCl}_{2}$ ) without ATP (adenosine triphosphate). An 80 fold molar excess of vector was added to the insert DNA. The agarose slice was melted at $68^{\circ} \mathrm{C}$ for $10 \mathrm{~min}$ and loaded in a mold slice apparatus before resolidifying the sample at room temperature. Agarose was then equilibrated in ligase buffer, containing $1 \mathrm{mM}$ ATP and $15 \mathrm{U}$ of T4 DNA ligase (Boehringer Mannheim, Germany)/g of gel. Ligation was performed at $4^{\circ} \mathrm{C}$ for $1 \mathrm{hr}$ and continued afterwards overnight at $14^{\circ} \mathrm{C}$. Ligated products were size-fractionated as mentioned above. A slice of agarose containing ligated parasite DNA from the compression zone was removed and equilibrated overnight in agarase buffer before transformation .

Transformation of yeast spheroplasts - A colony of yeast strain AB1380 (MATa ade2-1 ura3 can1-100 lys2-1 trp1 his5 $\psi+$ ) grown onto YPD agar plates (1\% yeast extract, $2 \%$ bactopeptone, $2 \%$ D-glucose, $1.5-2 \%$ bactoagar, $\mathrm{pH}$ 5.8) was cultured overnight in $200 \mathrm{ml}$ of YPD liquid medium at $30^{\circ} \mathrm{C}$ to obtain a culture density between 1 to $5 \times 10^{7}$ cells $/ \mathrm{ml}$. A series of tubes containing $1.5 \times 10^{9}$ cells were resuspended in $10 \mathrm{ml}$ SCEM buffer (2M sorbitol, $1 \mathrm{M}$ sodium citrate, $50 \mathrm{mM}$ EDTA, 14M $\beta$-mercaptoethanol, $\mathrm{pH} 8.0$ ), prepared and treated with serial dilutions of fresh zymolyase (Seikagaku Corporation, Tokyo, Japan). This treatment was performed at $30^{\circ} \mathrm{C}$ for 15 min with gentle agitation. Spheroplasts were placed in YPD containing $1 \mathrm{M}$ sorbitol. The cells were resuspended in STC buffer (1M sorbitol, $1 \mathrm{mM}$ Tris- $\mathrm{HCl} \mathrm{pH}$ 8.0, $1 \mathrm{mM} \mathrm{CaCl}$ ). Selected spheroplast preparations revealed an $\mathrm{OD}_{600}$ ratio $\mathrm{H}_{2} \mathrm{O}$ /sorbitol of 0.5 , presenting on microscopic analysis round cells in sorbitol, that were lysed when placed in $\mathrm{H}_{2} \mathrm{O}$. Ligated genomic DNA $(10 \mu \mathrm{l}$ per tube) was added to the spheroplast preparation $\left(1.5 \times 10^{7}\right.$ cells in 100 $\mu \mathrm{l})$ for $10 \mathrm{~min}$ at room temperature. Then, $1 \mathrm{ml}$ of 20\% PEG buffer (PEG 8000, $10 \mathrm{mM}$ Tris- $\mathrm{HCl} \mathrm{pH}$ 7.5) was added to the mixture for $10 \mathrm{~min}$ at room temperature. After centrifugation at $380 \mathrm{~g} / \mathrm{room}$ temperature, treated spheroplasts were resuspended in $150 \mu \mathrm{l}$ of SOS buffer (1M sorbitol, $0.25 \%$ yeast extract, $0.5 \%$ bactopeptone, $20 \mu \mathrm{g} / \mathrm{ml}$ uracil tryptophane, $20 \mathrm{mM} \mathrm{CaCl}_{2}, \mathrm{pH} 5.8$ ) and incubated at $30^{\circ} \mathrm{C}$ for $30 \mathrm{~min}$. Thereafter, they were plated on $1.5 \%$ top agar containing $1 \mathrm{M}$ sorbitol and lacking uracil onto SD $\mathrm{Ura}^{-}$plates $(0.9 \mathrm{M}$ sorbitol, $3 \% \mathrm{D}$ glucose, $0.67 \%$ yeast nitrogen base without amino acids, YNB,1.5-2\% bactoagar, pH $5.8+$ aminoacids). Plates were incubated at $30^{\circ} \mathrm{C}$ for at least six days. Red colonies were picked in double selection Ura- Trp ${ }^{-}$plates.

Preparation of DNA for YAC sizing - $100 \mu \mathrm{l}$ plugs were prepared in low melting point agarose from yeasts grown in overnight cultures at $30^{\circ} \mathrm{C}$ on YPD. The plugs were incubated for $3 \mathrm{hr}$ with SCEM (1M sorbitol, 50mM EDTA, 0.1M sodium citrate, $7 \mathrm{mM} \beta$-mercaptoethanol) with zymolyase (10 units/plug) at $37^{\circ} \mathrm{C}$. Then, they were washed and treated with $1 \mathrm{ml}$ PKB $(0.1 \mathrm{M} \mathrm{NaCl}, 50 \mathrm{mM}$ EDTA pH 8.0, 0.1M Tris-HCl pH 8.0, $1 \% \mathrm{~N}$ laurylsarcosine with $1 \mathrm{mg} / \mathrm{ml}$ of proteinase $\mathrm{K}$ ) at $50^{\circ} \mathrm{C}$ overnight and finally washed several times with TBE $0.5 \mathrm{x}$ to remove proteinase $\mathrm{K}$.

Analysis of YAC insert size - YACs were subjected to analytical electrophoresis on $1 \%$ low melting point agarose gels in $0.5 \mathrm{x}$ TBE by CHEFII migrations with pulse times of 60 to $90 \mathrm{sec}$., for 18 $\mathrm{hr}$ at $12^{\circ} \mathrm{C}, 220 \mathrm{v}$. After migration, the gel was stained with Ethidium Bromide and transferred to a nylon membrane (Hybond-N, Amersham, Buckinghamshire, UK). Membranes were prehybridized and then hybridized at $65^{\circ} \mathrm{C}$ with ${ }^{32} \mathrm{P}-\mathrm{dCTP}$ labelled T. cruzi total DNA.

Preparation of YAC pools - YACs were grown individually in AHC $(0.67 \%$ YNB, $0.1 \%$ casein, $0.002 \%$ adenine) for two days at $30^{\circ} \mathrm{C}$. Cultures were pooled in plates, arranged in columns and lines, centrifuged at $2000 \mathrm{rpm}$. Thereafter, they were used to prepare $100 \mu \mathrm{l}$ plugs with low melting point agarose. Plugs were incubated during 3 hr at $37^{\circ} \mathrm{C}$ in $10 \mathrm{ml}$ of SCEM/zymolyase (10 units/ plug), washed and treated with PKB $(0.1 \mathrm{M} \mathrm{NaCl}$, $50 \mathrm{mM}$ EDTA pH 8, $0.1 \mathrm{M}$ Tris-Cl pH 8, $1 \% \mathrm{~N}$ lauroyl sarcosine with $1 \mathrm{mg} / \mathrm{ml}$ proteinase $\mathrm{K}$ ) at $50^{\circ} \mathrm{C}$ overnight. The plugs were then washed several times with TBE $0.5 \%$ to remove proteinase K.

Polymerase chain reaction (PCR) analysis of YAC pools - For PCR assays, plugs containing YAC DNA were treated with agarase (Epicentre Technologies, France); the DNA was diluted in water, boiled for $10 \mathrm{~min}$ and finally stored at $-70^{\circ} \mathrm{C}$.

Primers for PCR were designed from DNA sequence data generated in our laboratory: SIRE sense primer 5' GATCGTGGGAGAGCTGGCTA 3', SIRE antisense primer 5' TCCTCCGGGCAGC TGGCCGGATCCTGA 3' (Vázquez 1994); HSP70 -sense primer 5' GGGCACCGGTAAGCGG AACCAG 3' and antisense primer 5' TCCTGA 
CGAAGACGACGGGTTCG 3' (Levy-Yeyati 1991); gp90 sense primer 5' TATAGGATCCCC TGTGAACACTCGG 3' and antisense primer 5' TTAGTCTAGATT TCCCGTCCTTGAT 3' (Franco 1994); JL7-H49 sense primer 5' GCGGA ATTC ATG GAGCAGGAGCGCAGG 3' and antisense primer 5' GCGGGATCCAACAAA GTGG CTGTCGTC 3' (Levin 1989, Cotrim 1995).

PCR reactions were carried out in $50 \mu \mathrm{l}$ volume reaction mixtures containing $200 \mu \mathrm{M}$ of each of the deoxyribonucleotide triphosphates (Pharmacia, Uppsala, Sweden), 1x Taq polymerase buffer (Perkin-Elmer, California, USA), 1.25U of Taq polymerase (Perkin Elmer; California, USA) and overlaid with $75 \mu \mathrm{l}$ of mineral oil (Perkin Elmer, California, USA). The reaction conditions for each assay were optimized for annealing temperature and for $\mathrm{MgCl}_{2}$ and primer concentrations. An initial denaturation step for $300 \mathrm{sec}$ at $94^{\circ} \mathrm{C}$ and a final step of $500 \mathrm{sec}$ at $72^{\circ} \mathrm{C}$ were included, and PCR was performed for 40 cycles.

Construction of BAC libraries - Partial digestion of DNA - Genomic T. cruzi DNA embedded in agarose, obtained as described above, was partially digested with Nde II and fractionated by a preparative PFGE (CHEF II). This PFGE was carried out in $1 \%$ low melting point at $12^{\circ} \mathrm{C}$ and $190 \mathrm{v}$ during $18 \mathrm{hr}$ with pulse times of $60 \mathrm{sec}$. Two libraries were constructed: BAC I, with size selected genomic fragments ranging from 100 to $300 \mathrm{~kb}$ and BAC II, with size selected fragments ranging from 200 to $400 \mathrm{~kb}$.

Preparation of BAC vectors - The BAC I library was constructed in pBAC108L vector (Shizuya 1992). The BAC II library was constructed in the pBAC derived vector, pBeloBAC11, that allows identification of transformed $E$. coli cells with blue-white phenotype. Plasmid BAC vectors were linearized with BamHI and dephosphorylated.

BAC ligation - 3-5 mm slices of agarose were prepared from size fractionated DNA and equilibrated in TE containing $50 \mu \mathrm{M} \mathrm{NaCl}$. Thereafter, agarose was melted at $65^{\circ} \mathrm{C}$ for $15 \mathrm{~min}$, equilibrated at $45^{\circ} \mathrm{C}$ for $3 \mathrm{~min}$, and incubated $1 \mathrm{hr}$ with agarase (1.5 U/100 $\mu$ l molten agarose). Finally, the tube was centrifugated to discard undigested agarose and the supernatant kept on ice. For ligation, insert and vector DNAs, in ratios 1:5 and 1:10, were heated briefly and cooled prior to addition of ligase buffer containing $1 \mathrm{mM}$ ATP and $1 \mathrm{U}$ of T4 DNA ligase in a final volume of $50 \mu$ l. Ligation was performed overnight at $16^{\circ} \mathrm{C}$. Ligated samples were dialyzed by drop dialysis against TE for $2 \mathrm{hr}$ before electroporation.

Preparation of electrocompetent cells - An aliquot from an overnight culture of E. coli DH10B was incubated in $600 \mathrm{ml}$ of $\mathrm{LB}$ at $37^{\circ} \mathrm{C}$ up to an
OD ${ }_{600 \mathrm{~nm}}$ of 0.4. Pelleted cells were washed several times in chilled water containing $10 \%$ glycerol and finally suspended in $2 \mathrm{ml}$ of water -glicerol (4 $\mathrm{x}$ $10^{7}$ cells $\left./ \mu \mathrm{l}\right)$. Electroporation was performed at pulses of 300v/5 millisec with suspensions of $8.4 \mathrm{x}$ $10^{8}$ cells and $3 \mu \mathrm{l}$ of ligation mix. Electroporated cells were then incubated in $1 \mathrm{ml}$ of SOC for $45 \mathrm{~min}$ at $37^{\circ} \mathrm{C}$, loaded in $\mathrm{LB}$ agar containing isopropylthio$\beta$-D-galactoside, IPTG, $100 \mu \mathrm{l}$ of $25 \mu \mathrm{g} / \mu \mathrm{l}$; 5bromo-4-chloro-3-indolyl- $\beta$-D-galactoside, $\mathrm{X}$ GAL, $100 \mu \mathrm{l}$ of $2 \%$, and chloramphenicol $(12.5 \mu \mathrm{g} /$ $\mathrm{ml}$ ) and incubated overnight at $37^{\circ} \mathrm{C}$.

BAC insert sizing - Minipreps were performed by an alkaline lysis method from overnight LBcloranphenicol cultures (Sambrook 1989). The DNA was digested with $5 \mathrm{U}$ of Not I for $4 \mathrm{hr}$ at $37^{\circ} \mathrm{C}$. After addition of loading buffer, the samples were electrophoresed in PFGE gels at $6 \mathrm{v} / \mathrm{cm}$ for $15 \mathrm{hr}$ with pulses of 20/20 sec in a CHEFII apparatus.

Storage of libraries - The YAC library was arrayed in 96 wells microplates, growing the cells into YPD and adding $20 \%$ glycerol, or in AHC agar microtiter plates, and storage at $-70^{\circ} \mathrm{C}$. BAC libraries were also arrayed in 96 wells microplates and stored in $20 \%$ glycerol after growing them into LB.

\section{RESULTS}

Construction of the YAC library of Trypanosoma cruzi CL-Brener - The basic features of the construction of large insert YAC libraries have already been described (Burke 1987, Dausset 1992). The cloning vector, pYAC4 (Smith 1994), carries sequences necessary for an artificial chromosome: the centromere (CEN4) and an autonomous replicating sequence (ARS). The telomeres were derived from the ciliate eukaryote, Tetrahymena, (Burke 1987). It carries selectable markers on each vector arm (TRP1 and URA3) as well as at the cloning site (SUP4; Burke 1987). In our experiments, the vector was propagated as bacterial plasmid and after modification and ligation to the insert DNA, transformed in yeast host cells as a linear molecule. The host strain AB1380 allowed to take advantage of the selective features of pYAC4 (Burke 1987). Consequently, transformants grew in medium lacking uracil and tryptophan and showed the red phenotype characteristic of the interrupted SUP4tRNA gene (Burke 1987). To apply the YAC cloning technology to the $T$. cruzi genome, we constructed a YAC library that includes YACs obtained in 4 successful transformations. It is composed of 2,770 clones arrayed in 30 microtiter plates and comprising approximately 10 genome equivalents.

To prepare the library it was of outmost importance to obtain intact genomic DNA from epimastigote cells. In a typical experiment, 3 x $10^{9}$ 
epimastigotes were resuspended in $3 \mathrm{ml}$ of low melting point agarose to prepare aproximately 30 blocks of $100 \mu \mathrm{l}$, each containing $20 \mu \mathrm{g}$ of genomic DNA. Integrity of the embedded genomic DNA was evaluated by PFGE. Indeed, more than 10 chromosomal bands, an intense compression zone and the lack of smears indicated an unaltered molecular karyotype (Cano 1995). Thereafter, conditions for partial EcoRI digestion were tested. The best results were obtained using $5 \mathrm{U} / \mu \mathrm{g}$ genomic DNA. To prepare genomic inserts, $100 \mu \mathrm{g}$ of genomic DNA was partially digested and size fractionated in preparative PFGE (Fig. 1). Fragments above $400 \mathrm{~Kb}$ were recovered within the compression zone of the gel and ligated to the pYAC4 vector arms in agarose as described in Material and Methods (Fig. 1). The ligation products were fractionated again by PFGE under similar conditions. After recovery and agarase treatment, size selected ligated DNAs were used to transform yeast spheroplasts. After each transformation, YACs were analyzed for molecular size (Figs 1, 2, 3 ).

Library organization and screening- Analysis of 60 randomly selected YACs revealed that the mean insert size was $365 \mathrm{~Kb}$. YACs were organized

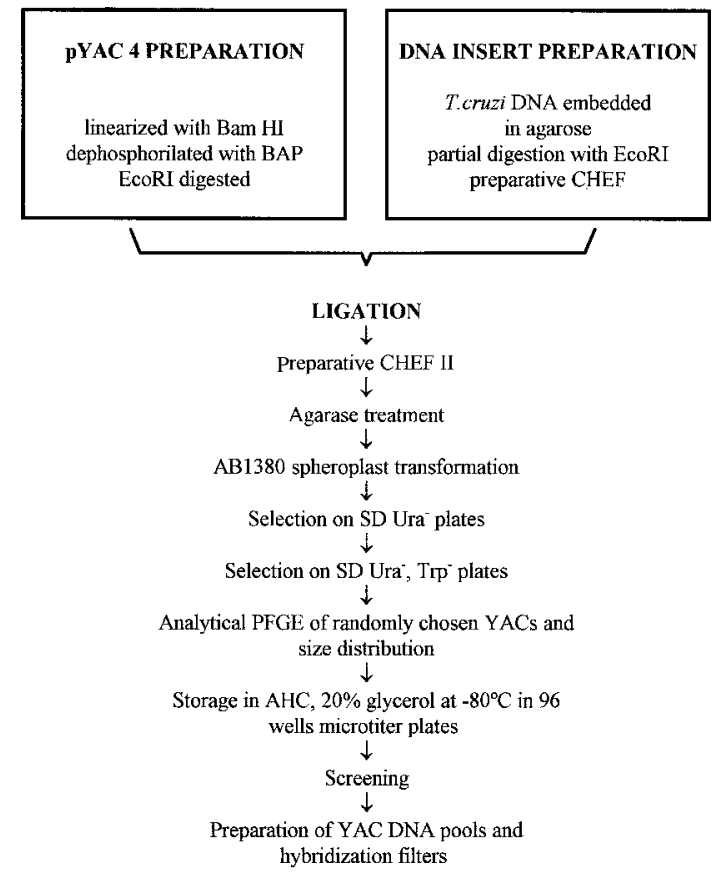

Fig. 1: YAC cloning procedure.

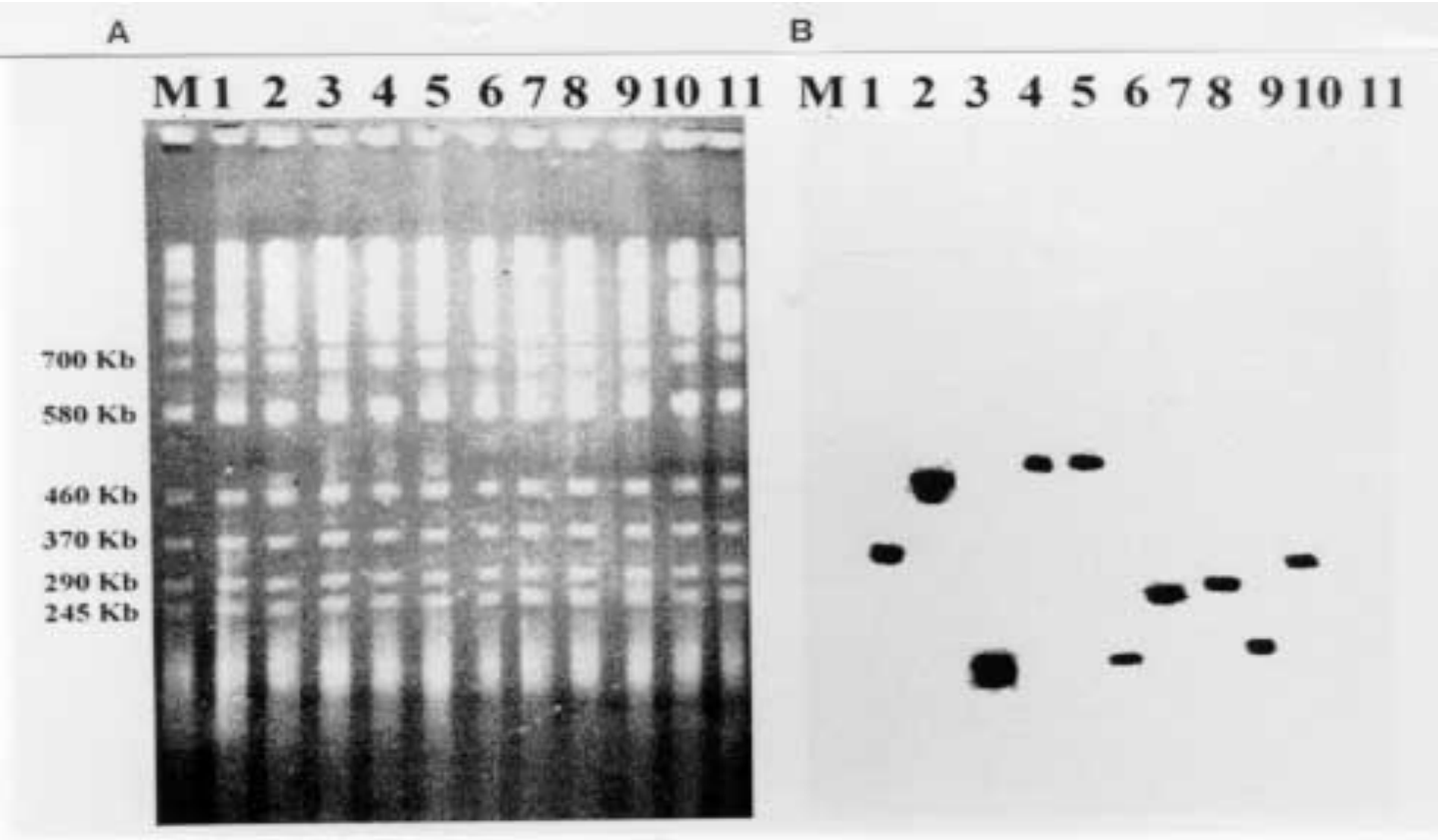

Fig. 2: analysis of sizes of YACs. Eleven randomly selected YAC clones were analyzed by (A) PFGE (conditions of the run are described in Materials and Methods); and (B) Southern blot. The Southern blots were probed with labeled Trypanosoma cruzi total DNA . 


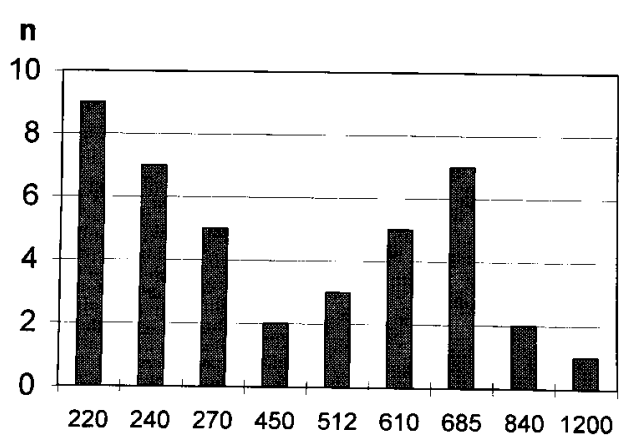

Fig. 3: size distribution of the Trypasomona cruzi YAC library. Fifty eight randomly chosen YACs were sized by PFGE as described in Materials and Methods; the mean size was calculated to be $365 \mathrm{~kb}$.

into an arrayed library in 96 wells microtiter plates. This arrangement offered advantages for screening, including avoidance of loss of slow growing clones and recovery of a maximum number of clones. It enabled also large scale screening using the PCR technique. Two procedures were used to evaluate the representation of different genomic sequences among YACs: one based in the preparation of filters representing 96 wells microplates, the second one based on PCR screening of three dimensional YAC DNA pools (Fig. 4).

Screening for repetitive sequences - One of the toughest challenges for any cloning system is the stable cloning of repetitive DNA. Interestingly enough, detection of these sequences allows a first evaluation of the representation of the library. Accordingly, we designed a PCR protocol to screen YAC DNA pools for a short interspersed repeti- tive element of the nuclear genome of T. cruzi, SIRE (Vázquez 1994) distributed in all chromosomes (Levin 1994, Cano 1995). The screening of pools of DNA from rows and columns of a microplate is shown in Fig. 4. In 14 out of 18 pools, SIRE or SIRE-derived amplification products were detected, indicating that for this microplate 55 out of 96 clones carried SIRE or SIRE related sequences. SIRE amplicons were also detected in 7 DNA pools, each one representing 4 microplates that cover the whole library.

Screening for gp90 genes - The gp90 gene is present in about 40 copies per haploid genome, and maps to 10 out of 20 chromosomal bands (Cano 1995). PCR 3 dimensional screening of pools covering 200 YACs allowed identification of 12 YACs containing gp90 genes. Confirmation of these results is shown in Fig. 5.

Screening for HSP70 genes - The HSP70 gene locus maps to chromosomal bands IX and X. PCR 3-dimensional screening of 400 YACs identified a YAC containing an HSP70 coding region.

Screening for the JL7-H49 genes - Genes coding for antigen JL7-H49 map to 2 homologous chromosomes, XVI and XVII, and define the JL7H49 locus linked to the JL8 gene (Cano 1995, Cano $\&$ da Silveira, personal communication). Hybridizations of filters covering 10 microplates permited detection of at least 3 JL7-H49 positive clones. JL7H49 amplicons of 199 bp were amplified from genomic DNA of the corresponding YACs.

These first results indicate that the representation of the library lies within expected ranges, with approximately $60 \%$ of clones containing SIRE sequences, about $10 \%$ containing gp 90 genes, and a

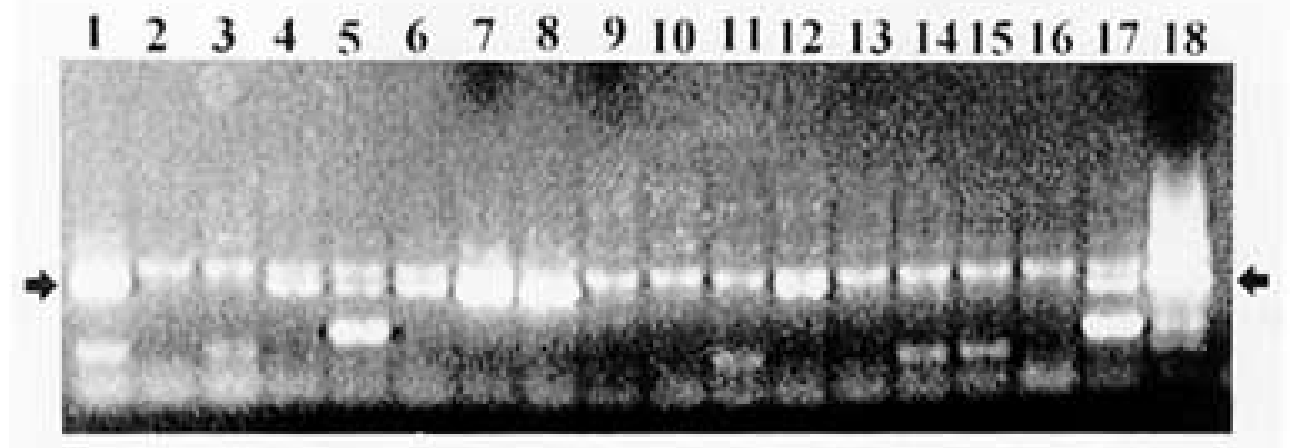

Fig. 4: screening of DNA pools of rows and columns from YACs ordered in the Tc2 microplate. Lanes 1 to 6, pools of YAC DNA from rows A, C, D, E, F and G; lanes 7 to 17, pools of YAC DNA from columns 1, 2, 3, 4, 5, 6, 7, 8, 9, 10, 11 and 12; lane 18, Trypanosoma cruzi DNA. The complete SIRE amplicon, 409 bp, is indicated by the arrows. Lanes 1, 3, 5, 11, 14, 15 and 17 showed SIRE related amplicons. SIRE-PCR was performed using 50 pmol of sense primer, 5' GATCGTGGGAGAGCTGGCTA 3', and 50 pmol of antisense primer, 5' TCCTCCGGGCAGCTGGCCGGATCCTGA 3' (Vázquez 1994), $200 \mu$ M deoxyribonucleotide triphosphates, $1 \mathrm{x}$ Taq polymerase buffer, $1.5 \mathrm{mM} \mathrm{Mg} \mathrm{Cl} 2$, and $1.25 \mathrm{U}$ of Taq polymerase in a $50 \mu 1$ volume reaction mixture overloaded with $75 \mu \mathrm{l}$ of mineral oil. Amplification was carried out for 40 cycles of $60 \mathrm{sec}$ at $94^{\circ} \mathrm{C}, 60 \mathrm{sec}$ at $55^{\circ} \mathrm{C}$ and $60 \mathrm{sec}$ at $72^{\circ} \mathrm{C}$. 


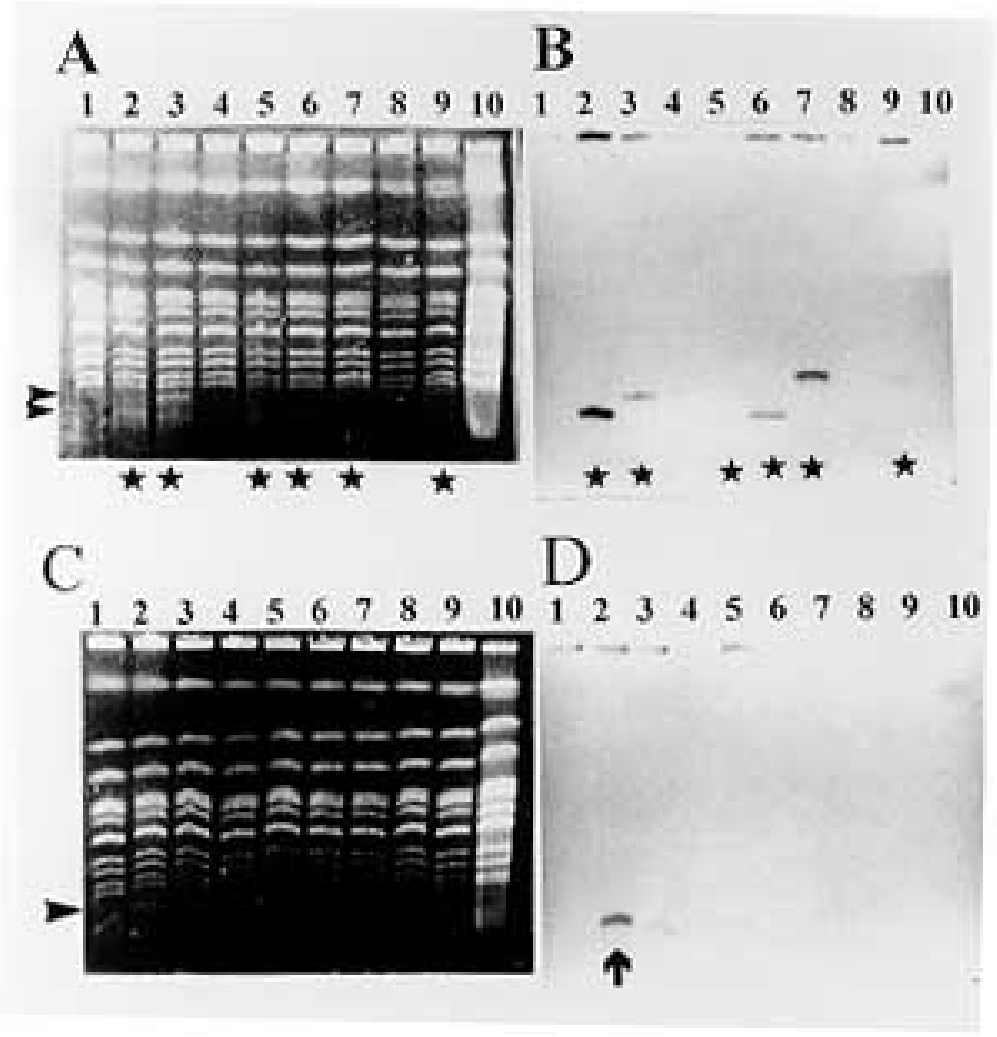

Fig. 5: screening of YACs with a gp90 probe: 3D-PCR screening of the YAC library with gp90 primers yielded positive signals for several YACs. Candidate YACs were electrophoresed (A, and C) blotted and hybridized with gp90 probe (B, and D). Stars and arrows indicate the presence of gp90 in YACs: A and B lanes 2, 3, 5, 6, 7, 9; C and D lane 2.

low percentage of YACs with JL7-H49 and HSP70 genes. The internal structures of the YAC clones containing gp90, JL7-H49, and the latter HSP70 were examined by comparing the length of restriction fragments from the YAC clones with those of the T. cruzi CL-Brener genomic DNA. In each case, the bands from the YAC clone were of the expected size and matched equivalent bands from the genomic DNA (Lorenzi H, Santos M, da Silverira F, Levin MJ, paper in preparation). In summary, the first experimental tests of the YAC cloning system imply that the studied YACs contain faithful, and genetically stable replicas of the $T$. cruzi nuclear genome. DNA of YACs do not appear to rearrange, but more detailed tests have to be carried out on a small scale and with a small number of clones in order to exclude the possibility that a certain percentage of YAC clones may be rearranged or unstable (Levin 1994, Brandariz 1995).

BAC library construction - Up to date, two types of BAC libraries have been constructed. The initial library of 9,000 clones, BAC I, was made using pBAC108L (Shizuya 1992). To prepare this library, intact genomic DNA was partialy digested with NdeII, size fractionated and ligated to dephosphorilated BamHI digested pBAC (Fig. 6). Ligated pBACs were used to transform competent $E$. coli cells by electroporation, as described in Materials and Methods. The recombinants were plated, colonies arrayed in 96 wells microplates, and stored for further analysis. A second library consisting of 3,000 clones (BAC II) was constructed using BamHI partially digested genomic DNA. Size selected DNA was recovered from gel using agarase, and ligated. Traditional colony lifts and hybridizations were used for screening and evaluation of insert size (Fig. 6). Representation and stability of BACs from the BAC I library was evaluated. In Fig. 7, the screening of a colony filter with the repetitive sequence E13 is shown. Sizing of the $\mathrm{E} 13$ positive $\mathrm{BACs}$ revealed a mean $\mathrm{BAC}$ insert size of $55 \mathrm{~kb}$. However, the mean insert size of 75 randomly selected BACs was not as high, reaching $20 \mathrm{~kb}$. Screening of 2,000 BACs with a retroposon probe (Martin 1995) allowed isolation of 32 BACs containing different portions of this 


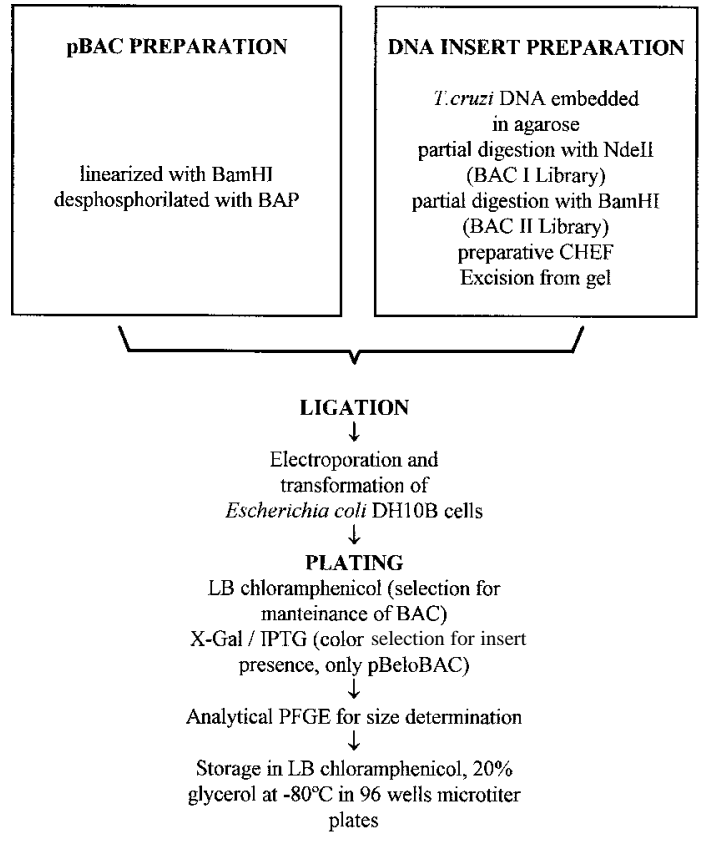

Fig. 6: BAC cloning protocol.
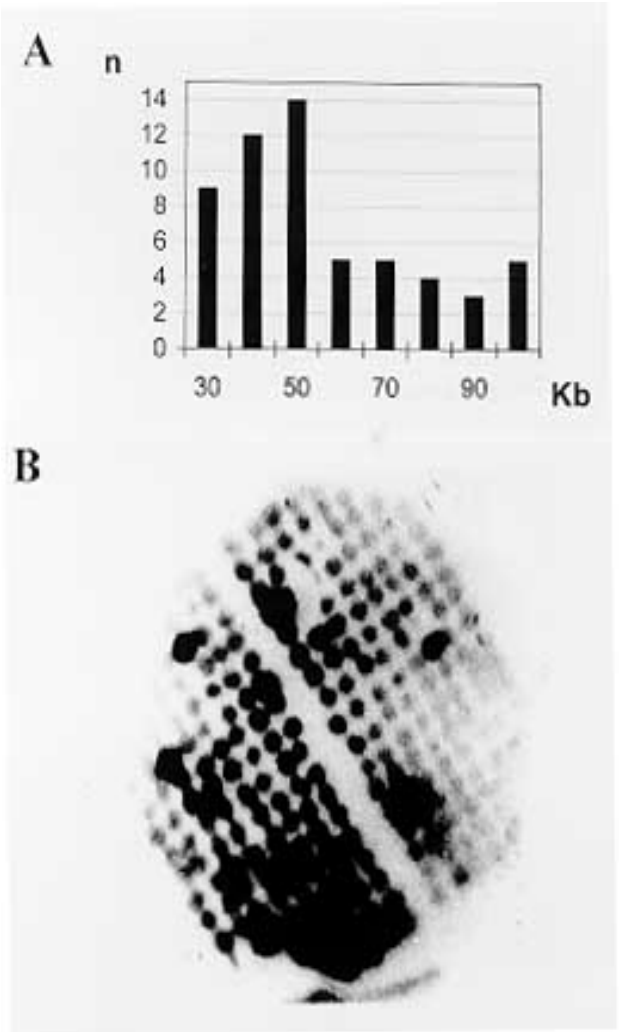

Fig. 7 - A: size distribution of E13 positive BACs from BAC1 library. A total of 59 BACs were analyzed. B: screening of a filter containing 236 BACs with an E13 probe (Requena 1993). element, in agreement with the number of copies of the retroposon in the genome and its chromosomal distribution (Cano 1995). The mean insert size of the BAC II library was slightly higher than that of the first library, $35 \mathrm{~kb}$. Several screenings revealed that repetitive elements such as the minisatelite sequence (Gonzalez 1984) were stably inserted. Aiming to increase the insert size of the cloned fragments, a third BAC library (BAC III) is being constructed.

\section{DISCUSSION}

STS are sites in the genome uniquely defined by its DNA sequence. At least three reasons justify their use as primary landmarks in genome mapping (Olson 1989). First, sequences defining STS markers are simple to generate and PCR assays using appropiate primers can be used to identify cloned fragments containing any STS. Second, STS markers can be used to confirm overlaps between clones, since two non chimeric clones containing the same STS must overlap. Third, the definition of STS markers in terms of unique DNA sequences frees the genome map from any particular collection of clones, since the presence of this STS can be assessed in any DNA sample or genomic library. Originally, STS were envisioned as sites chosen at random from anonymous DNA sequences. However, it seemed important to emphasize the use of already cloned sequences as STS markers. An attractive feature of this strategy is that the physical map assembled by means of the STS becomes annotated with biological data, generating valuable knowledge at the earliest phase of construction of the map.

Known genes - More than 135 T. cruzi gene sequences have been cloned and sequenced (de Miranda 1995) . Many of them have been mapped to the T. cruzi CL-Brener karyotype obtained by PFGE (Cano 1995, Henrikson 1996) and are actually been used as STS to identify YAC and BAC clones. Furthermore, the characterization of different forms of the same gene allowed to generate additional STS using PCR based single strand conformational analysis (SSCA; Vázquez 1996).

SIRE-associated sites (SAS) - An important class of STS markers in T. cruzi consists of sites adjacent to the SIRE. This element is dispersed in the genome and present in approximately 3,000 copies in the CL-Brener genome (Vázquez 1994). The general structure of this sequence is maintained, and can be used to generate STS by interSIRE assays, as proposed by Chumakov (1992) and Cohen (1993). More than 20 such SAS are available, and are being mapped to the electrophoretic karyotypes (Lorenzi 1996 ).

cDNA sequences or expressed sequence tags The other important source of STS consists of cod- 
ing sequences, and are called EST. For our project they are derived mainly from the normalized cDNA library, but other strategies to obtain ESTs are also being used: (a) 5' ESTs are being generated by PCR using different 3 ' primers and a common sense miniexon primer (Gonzalez personal communication) and (b) antigenic ESTs are being obtained by massive immunological screening of different lambda expression libraries (Fig. 8; Ghio \& Levin, unpublished results).

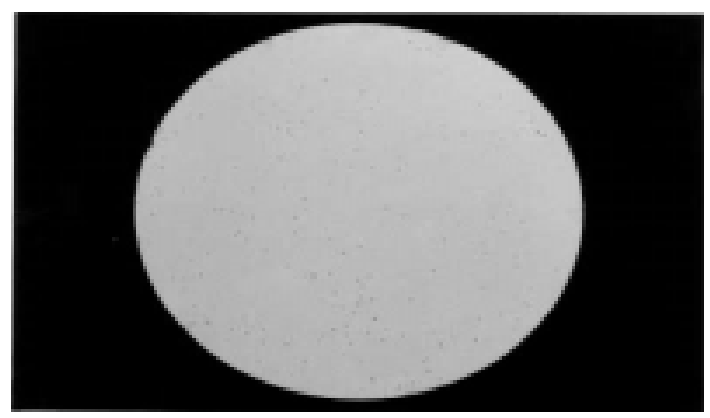

Fig. 8: screening of a $\lambda$ gt 11 library (Levy Yeyatti 1991) with a pool of sera from five chagasic patients with severe Chagas heart disease. The anti-Trypanosoma cruzi antibody titer of this mix of sera was 1: 2000 as measured by ELISA.The dilution of the pool of sera for screening was 1:400 (Levin 1989).

Standardized electroforetic karyotypes: an additional support for physical mapping - To establish the arrangements of all cloned fragments in a continuous stretch of DNA, it is of paramount importance to determine the chromosomal distribution of all markers generated within the framework of the T. cruzi genome project. This type of mapping has proved to be useful in defining linkage groups for the CL-Brener genome (Cano 1995, Henrikson 1996). Comparison of this STS distribution with the organization of the same markers in other strains is being used to determine which markers and/or cloned fragments consistently cosegregate on the same band, regardless of the strain. It is logical that, the more frequently markers cosegregate, the closer they must be. This particular type of genetic analysis is allowing the definition of linkage groups of markers and/or cloned genomic fragments, a basic complement and necessary support for construction of the physical map.
Chromosome specific contig assembly, or how to build the map - The first step in building the map of the T. cruzi genome is the use of STS markers as probes to isolate YACs and BACs. Each set of clones identified by a chromosome specific STS forms a contig, since they all contain the same chromosome specific sequence. In our case, contig assembly has begun around several well characterized loci, such as JL7-H49-JL8, and B11-B12-B13. Simultaneously, a modified version of the genome sampling strategy (GSS) (Smith 1994) has been developed. Isolated chromosomes XIX and XX. (Cano 1995) are being used as probes to hybridize high density filter membranes to organize YACs and BACs in chromosome specific subsets. Chromosome specific markers, such as those obtained by inter-SIRE PCR, SAS, are being used to confirm the chromosome specificity of the cloned genomic fragments (Lorenzi 1996). Since BACs are easy to manipulate and cloned DNA is easy to prepare, the first effort concerning the assembly of cloned fragments to establish contigs is based on BACs. Each group of chromosome specific BACs, identified by a particular STS, forms a contig, since they all contain the same STS. End specific probes will be used to extend contig assembly. Ideally YACs will be used to connect established BAC contigs to yield a continuous physical map of each chromosome.

We conclude that large insert libraries in YAC and BAC vectors are now available.

They are invaluable tools for the construction of the physical map of this complex genome. More generally, they have to be considered as a common resource for research in Chagas disease.

\section{REFERENCES}

Ajioka J, Swindle 1993. The calmodulin-ubiquitin associated genes of Trypanosoma cruzi: their identification and transcription. Mol Biochem Parasitol 57: 127- 36

Aldao RR 1993. Ibero-American meeting on molecular aspects of Chagas' disease and leishmaniasis. Biol Res 26: 1-2.

Andrews NW 1993. Living dangerously: How Trypanosoma cruzi uses lysosomes to get inside host cells, and then escapes into the cytoplasm. Biol Res 26: 65-67.

Brandariz S 1995. The Trypanososma cruzi genome project: Genome Sequence Sampling (GSS) strategy for hight resolution physical mapping. Mem Inst Oswaldo Cruz 90 (Suppl): 20-21.

Burke DT 1987. Cloning of large segments of exogeneous DNA into yeast by means of artificial chromosome vectors. Science 236: 806-812.

Cano MI 1995. Molecular karyotype of Trypanosoma cruzi CL-Brener reference clone of the T. cruzi genome project. Mol Biochem Parasitol 71: 273-278.

Cohen D 1993. A first-generation physical map of the 
human genome. Nature 336: 698-701.

Cotrim P 1990. Organization and expression of the gene encoding an immunodominant repetitive antigen associated to the cytoeskeleton of Trypanosoma cruzi. Mol Biochem Parasitol 71: 89- 98.

Chagas C 1909. Nova tripanosomiaze humana. Estudos sobre a morfolojia e o ciclo evolutivo do Schyzotrypanum cruzi n. g., n. sp., ajente etiolojico de nova entidade morbida do homem. Mem Inst Oswaldo Cruz 1: 159-218.

Chumakov I 1992. Continuum of overlapping clones spanning the entire human chromosome 21q. $\mathrm{Na}$ ture 359: 380- 386.

Dausset J 1992. The CEPH YAC Library. Behring Inst Mitt 91: 13-20.

de Bruin D 1992. Characterization of yeast artificial chromosomes from Plasmodium falciparum: Construction of a stable, representative library and cloning of telomeric DNA fragments. Genomics 14: 332- 339.

de Miranda 1995. Construction of "TCRUZIDB", an integrated genome database for Trypanosoma cruzi. Mem Inst Oswaldo Cruz 90 (Suppl): 119.

Dong J 1995. Generation of large DNA T. cruzi genomic libraries using bacterial artificial chromosomes. Mem Inst Oswaldo Cruz 90 (Suppl): 21.

Franco FR 1994. Characterization of a cDNA clone encoding the Carboxy-terminal domain of a 90kilodalton surface antigen of Trypanosoma cruzi metacyclic trypomastigotes. Infect Imm 61: 41964201.

Gomes NA 1995. Down-regulation of T-Cell activation in vitro and in vivo by Glycoino-sitolphospholipids (GIPLS) from Trypanosoma cruzi: Mapping of the suppressive determinant to the ceramide domain. Mem Inst Oswaldo Cruz, 90 (Suppl): 74-75.

González A 1984. Minichromosomal repetitive DNA in Trypanosoma cruzi : its use in a high-sensitive parasite detection assay. Proc Nat Acad Sci 81: 3356-3360.

González A, Moro A 1995. Role of TCMIP in the invasion of nonphagocytic cells by Trypanosoma cruzi. Mem Inst Oswaldo Cruz, 90 (Suppl): 54-55.

Henriksson L 1996. Karyotype Variability in Trypanosoma cruzi. Parasitol Today 12: 108-114.

Hontebeyrie-Joskowicz M, Minoprio P 1991. Chagas' disease: Trypanosoma cruzi vs the host immune system. Inst Pasteur Res Immunol 142: 125-126.

Lanzer M 1993. Transcriptional diferences in polymorphic and conserved domains of a complete cloned $P$. falciparum chromosome. Nature 361: 654-657.

Levin MJ 1989. Identification of major Trypanosoma cruzi antigenic determinants in chronic Chagas' heart disease. Am J Trop Med Hyg 41: 530-539.

Levin MJ 1991. Recombinant Trypanosoma cruzi antigens and Chagas' disease diagnosis: analysis of a workshop. FEMS Microbiol Immunol 89: 11-20.

Levin MJ 1994. Toward the physical map of the Trypanosoma cruzi nuclear genome. Mem Inst Oswaldo Cruz 89 (Suppl) : 17-18.

Levy-Yeyati P 1991.The $70 \mathrm{kDa}$ heat shock protein is a major antigenic determinant in human Trypanosoma cruzi-Leishmania braziliensis braziliensis mixed infection. Immunol Lett 31: 27-34.

Lorenzi H 1996. Generation of SIRE-based STSs and
ESTs for the Trypanosoma cruzi Genome Project. Genome Mapping \& Sequencing Meeting 1996, Book of Abstracts, Cold Spring Harbor Laboratory 151.

Martín F 1995. Characterization of a Non-long Terminal Repeat Retrotransposon cDNA (L1Tc) from Trypanosoma cruzi : Homology of the First ORF with the Ape Family of DNA Repair Enzymes. $J$ Mol Biol 247: 49-59.

Mosca W, Briceño L 1993. Cell mediated immune response in patients with Chagas. Correlation with the presence of chagasic cardyomiophaty. Biol Res 26: 225-231.

Olson MV 1989. A common language for physical mapping of the human genome. Science 245: 1434.

Pereira-Chioccola VL 1995. Can immunity to transsialidase and sialic acid acceptors control parasitism of Chagas' disease? Mem Inst Oswaldo Cruz 90 (Suppl): 11.

Requena JM 1993. Isolation of Trypanosoma cruzi specific nuclear repeated DNA sequences. Biol Res 26 : 11-18.

Rosenbaum MB 1964. Chagasic miocardiopathy. Progr Cardiovas Dis 7: 199-225.

Sambrook J 1989. Molecular Cloning. A laboratory manual. 2nd ed. Cold Spring Harbor Laboratory Press, New York, 1.38-1.39.

Shizuya H 1992. Cloning stable maintenance of 300kilobase-pair fragments of human DNA in Escherichia coli using an F-factor-based vector. Proc Natl Acad Sci 89: 8794-8797.

Smith DR 1994. Vectors and host strains for cloning and modification of yeast artificial chromosomes, p. 131. In D Nelson, B Brownstein (eds), YAC Libraries, A User's Guide, New York, USA.

Solari AJ 1980. The 3-dimensional fine structure of mitotic spindle in Trypanosoma cruzi. Chromosoma 78: 239-255.

The Wellcome Trust Malaria Genome Collaboration 1995. The Plasmodium falciparum Genome Project: A Resource for Researchers. Parasitol Today 11: 1- 7.

Tibayrenc M, Ayala F 1988. Isozyme variability in Trypanosoma cruzi, the agent of Chagas' disease: Genetical, Taxonomical, and Epidemiological significance. Evolution 42: 277-292.

Urményi TP 1995. Trypanosoma cruzi Genome Project: Contruction of cDNA Libraries and Generation of expressed sequence tags. Mem Inst Oswaldo Cruz 90 (Suppl): 113.

Urbina J 1995. Current perspectives in the treatment of Chagas disease using sterol biosynthesis inhibitors. Mem Inst Oswaldo Cruz 90 (Suppl): 41.

Vázquez MP 1994. A short interspersed repetitive element provides a new 3' acceptor site for trans-splicing in certain ribosomal P2 protein genes of Trypanosoma cruzi. Mol Biochem Parasitol 64: 327-336.

Vázquez, MP 1996. Detection of polymorphism in the Trypanosoma cruzi Tcp 2 b gene family by Single Strand Conformation Analysis (SSCA). Gene 180: 43-48.

Wang M 1994. Construction and Characterization of a Human Chromosome 2-Specific BAC Library. Genomics 24: 527- 534. 